\title{
Acute stress disorder and defense mechanisms: a study of physical trauma patients admitted to an emergency hospital
}

\author{
Transtorno de estresse agudo e mecanismos de defesa: pesquisa com \\ pacientes que sofreram trauma físico atendidos em um hospital de emergência
}

\author{
Márcia Rosane Moreira Santana, ${ }^{1}$ Cleonice Zatti, ${ }^{1}$ Mariana Lunardi Spader, ${ }^{2}$ Bibiana Godoi Malgarim, ${ }^{1}$ Emílio Salle, ${ }^{3}$ \\ Renato Piltcher, ${ }^{3}$ Keila Maria Mendes Ceresér, ${ }^{4}$ Andre Goettems Bastos, ${ }^{5}$ Lúcia Helena Freitas ${ }^{6,7}$
}

\begin{abstract}
Introduction: Acute stress disorder (ASD) encompasses a set of symptoms that can arise in individuals after exposure to a traumatic event. This study assessed the defense mechanisms used by victims of physical trauma who developed ASD.

Method: This was a controlled cross-sectional study of 146 patients who suffered physical trauma and required hospitalization. A structured questionnaire was used to evaluate ASD symptoms based on DSM-5 diagnostic criteria, in addition to the Defense Style Questionnaire (DSQ).

Results: Ten participants (6.85\%) received a positive diagnosis of ASD, and 136, (93.15\%) a negative diagnosis. The majority of the sample consisted of men with median age ranging from 33.50 to 35.50 . The most prevalent defense mechanisms among the 10 patients with ASD were cancellation and devaluation, which belong to the neurotic and immature factors, respectively. Positive associations between the presence of symptoms from criterion B of the DSM-5 and defense mechanisms from the DSQ were found. These included the mechanisms of undoing, projection, passive aggression, acting out, autistic fantasy, displacement, and somatization.

Conclusion: Patients with ASD employed different defense mechanisms such as undoing and devaluation when compared to patients not diagnosed with ASD. These results mark the importance of early detection of ASD symptoms at a preventative level, thereby creating new possibilities for avoiding exacerbations related to the trauma, which represents an important advance in terms of public health.
\end{abstract}

Keywords: Symptom, acute stress disorder, defense mechanisms, stressful events.

\section{Resumo}

Introdução: O transtorno de estresse agudo (TEA) reúne um conjunto de sintomas que pode surgir nos indivíduos após exposição a um evento traumático. Este estudo verificou a relação entre o estilo defensivo e o desenvolvimento de TEA e seus sintomas em uma amostra de pacientes que sofreram trauma físico.

Métodos: Este estudo transversal controlado envolveu 146 pacientes que sofreram trauma físico e necessitaram hospitalização. Um questionário estruturado foi utilizado para avaliar sintomas de TEA, baseado nos critérios diagnósticos do DSM-5, além do Questionário de Estilo Defensivo (Defense Style Questionnaire - DSQ).

Resultados: Dez (6,85\%) pacientes tiveram diagnóstico positivo para TEA, e 136 (93,15\%), diagnóstico negativo. A maioria da amostra foi composta por homens com idade mediana variando de 33,50 a 35,50. Nos 10 pacientes positivos para TEA, destacou-se a maior utilização de mecanismos de defesa de anulação e desvalorização, pertencentes ao fator neurótico e ao fator imaturo, respectivamente. Foram observadas associações positivas entre presença de sintomas de TEA do critério $B$ do DSM-5 e os mecanismos de defesa do DSQ, sobretudo nos mecanismos de anulação, projeção, agressão passiva, acting out, fantasia autística, deslocamento e somatização.

Conclusão: Pacientes com TEA utilizaram mais mecanismos de defesa do tipo anulação e desvalorização quando comparados aos pacientes sem diagnóstico de TEA. Ressalta-se a importância da deteç̧ão precoce de sintomas de TEA a fim de evitar outros agravos relacionados ao trauma, o que representa uma importante evolução em termos de saúde pública.

Descritores: Sintoma, transtorno estresse agudo, mecanismos de defesa, eventos estressantes.

\footnotetext{
${ }^{1}$ Programa de Pós-Graduação em Ciências Médicas: Psiquiatria, Universidade Federal do Rio Grande do Sul (UFRGS), Porto Alegre, RS, Brazil. ${ }^{2}$ Faculdade de Medicina, UFRGS, Porto Alegre, RS, Brazil. ${ }^{3}$ Hospital de Pronto Socorro de Porto Alegre, Porto Alegre, RS, Brazil. ${ }^{4}$ Laboratório de Psiquiatria Molecular, Hospital de Clínicas de Porto Alegre (HCPA), Porto Alegre, RS, Brazil. ${ }^{5}$ Departamento de Psicologia, Pontifícia Universidade Católica do Rio Grande do Sul (PUCRS), Porto Alegre, RS, Brazil. ${ }^{6}$ Serviço de Psiquiatria, HCPA, Porto Alegre, RS, Brazil. ${ }^{7}$ Departamento de Psiquiatria e Medicina Legal, Faculdade de Medicina, UFRGS, Porto Alegre, RS, Brazil.

Submitted Oct 11 2016, accepted for publication May 092017.

Suggested citation: Santana MR, Zatti C, Spader ML, Malgarim BG, Salle E, Piltcher R, et al. Acute stress disorder and defense mechanisms: a study of physical trauma patients admitted to an emergency hospital. Trends Psychiatry Psychother. 2017;39(4):247-256. http://dx.doi.org/10.1590/2237-6089-2016-0071
} 


\section{Introduction}

The concept of trauma is used to define occurrences in one's life characterized by their intensity and one's incapacity to respond to them in a suitable manner, by the upset they cause, and by the durable psychopathological effects they produce in term of the patient's psychological organization. ${ }^{1}$ Sigmund Freud (1920/1996), in his research on neuroses, established the bases of this concept, employing the term to refer to psychological reactions in the face of railway accidents and the impact of death on war veterans. Thus, the term "trauma," until then used to refer to bodily injuries, started to be applied to psychological phenomena, bringing the latter into the realm of casualty and treatment. ${ }^{2}$

This new picture, which emerged from the recognition of symptomatologic phenomena arising in the contexts of war - in particular, the World Wars and the Vietnam War - fostered the formulation in the 1980 s of diagnostic criteria for post-traumatic stress disorder (PTSD) as a dimensional category. It referred to various symptoms associated with trauma experienced in war, ${ }^{3,4}$ according to the 1980 Diagnostic and Statistical Manual of Mental Disorders, Third Edition (DSM-III). ${ }^{5}$

In the subsequent edition, the DSM-IV, acute stress disorder (ASD) appeared as a separate diagnostic category, describing symptoms consistent with psychological disturbances similar to those of PTSD, which occur in many individuals after a trauma, but with a maximum duration of one month. This came to be an important diagnosis as well, since ASD seemed to predispose to PTSD. ${ }^{6-8}$ Finally, according to the 2013 DSM $-5,{ }^{9}$ the prevalence of ASD in a population exposed to a serious traumatic stress depends on the severity and persistence of the trauma and the degree of exposure to it. Studies highlight that the prevalence of ASD can vary from 7 to $28 \%$ among trauma sufferers. ${ }^{10}$ Researchers have diagnosed ASD in $16 \%$ of 62 hospitalized motor vehicle accident victims and in $14 \%$ of 79 patients hospitalized after traumatic brain injury. ${ }^{11,12}$ A longitudinal study using DSM-IV criteria found evidence for ASD in $10 \%$ of a total of 1,129 patients from five large trauma centers in Australia who suffered traumatic injury. ${ }^{13}$ This was corroborated by another study that investigated latent structures of ASD in 450 employee-victims of bank assault and found the same ASD prevalence rate of $10 \% .^{14}$

From a psychoanalytic perspective, the ego, when faced with demands inherent to internal and external realities, activates defense mechanisms to try to reconcile impulsive needs with reality. In the context of trauma, the core functions of defense mechanisms are to moderate emotional levels of stress, providing time for the individual to deal with the trauma, and to help them handle inevitable losses. Defense mechanisms also function as psychological mechanisms that seek a balance between desires, needs, and individual impulses on the one hand, and the prohibitions and demands of external reality or the superego on the other. ${ }^{15}$ When well-adapted, defense mechanisms are positively associated with happiness, psychosocial maturity, occupational success, stable relationships, and absence of psychopathology. ${ }^{16,17}$

The literature stresses the importance of studies on defense mechanisms, as they are an indication of risk for disorders after a trauma. Some people are more vulnerable than others to potentially traumatic situations. Conversely, some deal better with negative experiences. These people will demonstrate a higher level of competency, self-esteem, and feelings of selfefficacy in the face of adversity, revealing more positive attitudes towards life and showing the capacity to give meaning to their experiences. The qualities of the defense mechanisms used by an individual are related to their ability to adapt to the external reality. In this sense, authors continue to emphasize that defenses do not deny or distort the source of the conflict itself, but rather enhance its mitigation. 9,16,17

The objective of this study was to explore and assess the relationship between the style of defenses/ defense mechanisms and the development of ASD and its symptoms in a sample of patients who experienced physical trauma. The study is warranted as it addresses a novel area not merely in the realm of trauma in general, but specifically in the field of ASD.

\section{Method}

\section{Participants}

Data collection was performed at a referral emergency hospital for physical trauma in Porto Alegre, state of Rio Grande do Sul, southern Brazil. Study participants were patients over 16 years of age, victims of sufficiently severe physical trauma, with recommended hospitalization for a minimum of 48 hours. The hospitalization duration criterion, in addition to providing a minimum level of severity for similar cases, was important to allow the investigation of the diagnosis of ASD according to DSM-5 diagnostic criteria. ${ }^{9}$

Patients who refused to participate in the study or who were unable to do so due to their clinical condition were excluded from the sample. Patients hospitalized due to suicide attempt were also excluded as the authors felt that suicidal patients required different care regarding their psychopathology. A total of 146 participants were 
assessed (136 with a negative diagnosis for ASD and 10 with a positive diagnosis).

\section{Instruments}

Participants were assessed using a structured interview based on DSM-5 criteria to verify the presence of ASD. After diagnosis, participants were divided into two groups (with ASD and without ASD).

Then, statistical analyses (Kolmogorov-Smirnov test, $t$-test, Mann-Whitney $U$ test, and Spearman's rho, with significance set at 0.05) were performed and revealed the prevalence of association between the defense mechanisms employed by individuals and the symptoms of ASD from criterion B of the DSM- 5 .

Clinical and demographic data were assessed by means of a structured questionnaire. The Socioeconomic Level Scale (Escala de Nível Socioeconômico - ENS) proposed by Associação Brasileira de Institutos de Mercado, was used to define the socioeconomic profile of the groups. This scale provides an objective economic classification based on family consumer goods, with five divisions: A, B, C, D, and E. ${ }^{18}$

Defense mechanisms were evaluated using the Defensive Style Questionnaire (DSQ), ${ }^{19}$ subsequently revised $^{20}$ and reorganized ${ }^{21}$ as the DSQ-40. The primary translation and adaptation of the DSQ to Brazilian Portuguese was done by Andrade as part of a reliability study. ${ }^{22,23}$ In 2004, Blaya et al., who evaluated defense mechanisms using the Portuguese version of the DSQ-40, ${ }^{24}$ undertook a preliminary adaptation and validation study.

The DSQ is an objective questionnaire and can be self-administered. It evaluates 20 individual defenses, calculating the mean of 10 items per defense mechanism. Each item is ranked on a scale ranging from 1 to 9 , with 1 indicating "strongly disagree" and 9 indicating "strongly agree." Defenses are divided into three factors: mature (sublimation, humor, anticipation, and suppression), neurotic (undoing, pseudo-altruism, idealization, and reaction formation), and immature (projection, passive aggression, acting out, isolation, devaluation, autistic fantasy, denial, displacement, dissociation, splitting, rationalization, and somatization). Score factors were calculated using the mean defense scores belonging to each factor. In this study, specialists had a mean allocation of experts' correlation to each defense of $89 \%$, and of $100 \%$ to the mature, neurotic, and immature factors. ${ }^{24}$

Psychiatric comorbidities were evaluated using the Mini-International Neuropsychiatric Interview (MINI), which consists of a short, standardized diagnostic interview compatible with the DSM-III-R/IV and also with the International Classification of Diseases, 10th edition (ICD-10).

\section{Statistical analysis}

The Kolmogorov-Smirnov test was used to assess the distribution of variables. Those with a normal distribution were presented as mean \pm standard deviation, while those asymmetrically distributed were described using interquartile ranges. ${ }^{25}$ Means were then compared using a $t$-test for independent samples, whereas medians were compared using the Mann-Whitney $U$ test. Categorical variables were described using absolute and relative frequencies and analyzed using the chi-square test or Fisher's exact test. Associations between the variables were assessed using Spearman's rho. A significance level of 0.05 was adopted.

\section{Ethical considerations}

This study is part of the research project entitled "Evaluation of acute stress disorder and post-traumatic stress disorder in patients hospitalized for physical trauma," which was approved by the research ethics committee of Hospital de Clínicas of Porto Alegre (protocol no. 126.555, CAAE 06900412.0.0000.5327) and followed all ethical recommendations of the Brazilian National Health Council Resolution 196/96. Participants and/or guardians obtained all necessary information beforehand, and any doubts concerning the study were completely clarified. After this procedure, those who agreed to participate in the study signed an informed consent form. The anonymity of all patients is protected.

\section{Results}

The final sample comprised 146 physical trauma victims, of which 136 (93.15\%) had a negative diagnosis for ASD and $10(6.85 \%)$ had a positive diagnosis. This unequal group distribution was caused merely by the prevalence of ASD diagnosis in the target population when exploring it in using a naturalistic approach. This issue was controlled using unpaired statistical methods for asymmetrical groups. Conversely, sociodemographic data revealed that the sample was homogeneously distributed, being predominantly male and having a median age in the range of 33.50 to 35.50 . In the ASD-negative group, more than half of the participants were single, employed $(46.6 \%)$, and had a median of 8.0 years of education. In the ASD-positive group, in turn, participants were mainly single $(30 \%)$, employed $(60 \%)$, with a median of 10.0 years of schooling. In both groups, C was the predominant economic class, and the most common reason for hospitalization was traffic accident. These data are shown in Table 1.

The Kolmogorov-Smirnov test was used to assess variable distribution and to investigate in what way the 
distribution of quantitative variables was asymmetric. Asymmetric variables were described using interquartile ranges and compared using the Mann-Whitney $U$ test; categorical variables were described using absolute and relative frequencies and analyzed using the chi-square test or Fisher's exact test. A significance level of 0.05 was adopted.

Table 2 shows that the defense mechanisms undoing and devaluation showed statistically significant differences between the groups: both were more prevalent in individuals who developed ASD when compared with those with a negative diagnosis.

The study also proposed to analyze ASD (criterion B of the DSM-5) and its relation to defense mechanisms, as seen in Table 3.

For this analysis, the Kolmogorov-Smirnov test was performed to assess the distribution of the variables. Those with a normal distribution were described as mean \pm standard deviation, while those with an asymmetric distribution were described using interquartile ranges. Means were compared using $t$-test for independent samples, while medians were compared using the MannWhitney $U$ test. A significance level of 0.05 was used.

As seen in Table 3, patients with ASD symptoms from criterion B of the DSM-5 showed significantly higher levels of the following defense mechanisms: idealization, undoing, projection, passive aggression, autistic fantasy, and somatization.

When using Spearman's rho $(p<0.05)$ to investigate possible associations between positive symptoms from criterion $B$ of the DSM-5 and the defense mechanisms assessed in the DSQ (Table 4), we found that undoing, projects, passive aggression, acting out, autistic fantasy, displacement, and somatization showed significant correlations. Statistically significant correlations were also observed with the mechanisms

Table 1 - Clinical and demographic data of the two groups of patients assessed for ASD

\begin{tabular}{|c|c|c|c|}
\hline \multirow[b]{2}{*}{ Variable } & \multicolumn{3}{|c|}{ ASD diagnosis } \\
\hline & Negative $(n=136)$ & Positive $(n=10)$ & $\mathbf{p}$ \\
\hline Median age (years), median $\left(\mathrm{p}_{25}-\mathrm{p}_{75}\right)$ & $33.50(24.50-46.0)$ & $35.50(24.0-44.0)$ & 0.850 \\
\hline Male & $118(86.8)$ & $7(70.0)$ & 0.158 \\
\hline Marital status & & & 0.100 \\
\hline Single & $70(51.5)$ & $3(30.0)$ & \\
\hline Married & $55(40.4)$ & $6(60.0)$ & \\
\hline Divorced/separated & $10(7.4)$ & $0(0)$ & \\
\hline Widowed & $1(0.7)$ & $1(10.0)$ & \\
\hline Employment status $\left(n=133^{*}\right)$ & & & 0.645 \\
\hline Employed & $62(46.6)$ & $6(60.0)$ & \\
\hline Unemployed & $20(15.0)$ & $1(10.0)$ & \\
\hline Retired & $5(3.8)$ & $1(10.0)$ & \\
\hline On leave & $10(7.5)$ & $1(10.0)$ & \\
\hline Self-employed & $32(24.1)$ & $1(10.0)$ & \\
\hline Student & $4(3.0)$ & $0(0)$ & \\
\hline Median education (years), median $\left(p_{25}-p_{75}\right)$ & $8.0(6.0-11.0)$ & $10.0(5.0-11.0)$ & 0.906 \\
\hline Hospitalization reason $\left(n=117^{*}\right)$ & & & 0.776 \\
\hline Firearm injury & $15(12.8)$ & $0(0)$ & \\
\hline Melee weapon injury & $12(10.3)$ & $1(11.1)$ & \\
\hline Aggression & $25(21.4)$ & $2(22.2)$ & \\
\hline Traffic accident & $53(45.3)$ & $6(66.7)$ & \\
\hline Work accident & $12(10.3)$ & $0(0)$ & \\
\hline Socioeconomic level & & & 0.483 \\
\hline A & $7(5.1)$ & $1(10.0)$ & \\
\hline B & $47(34.6)$ & $2(20.0)$ & \\
\hline C & $69(50.7)$ & $5(50.0)$ & \\
\hline $\mathrm{D}$ & $10(7.4)$ & $2(20.0)$ & \\
\hline $\mathrm{E}$ & $3(2.2)$ & $0(0)$ & \\
\hline
\end{tabular}

Sample size is smaller in some items because not all participants answered all questions.

Data presented as $\mathrm{n}(\%)$, unless otherwise specified.

$\mathrm{ASD}=$ acute stress disorder; $\mathrm{p}_{25}-\mathrm{p}_{75}=25$ th-75th percentile.

250 - Trends Psychiatry Psychother. 2017;39(4) 
anticipation, pseudo-altruism, idealization, reaction formation, devaluation, denial, and splitting, even though these were not as intense as the previously mentioned correlations.

Variables were described using relative and absolute frequencies and analyzed using the chi-square or Fisher's exact test. A significance level of 0.05 was adopted.

\section{Discussion}

The present results showed that 10 (6.85\%) participants presented a positive diagnosis for ASD. This is slightly below the results reported in previous studies (incidence of ASD diagnosis ranging from 8 or $31 \%)^{26-28}$ Still, the sociodemographic characteristics of the two groups were homogeneous, with no statistically significant differences in age, gender, marital status, work situation, years of education, source of trauma, or socioeconomic level (Table 1 ). Participants were mainly male, young, single, employed, with a mean of 8 years of education, belonged to socioeconomic class $\mathrm{C}$, and had been involved in a traffic accident.
Studies suggest that the seriousness of psychic damage produced by real trauma depends much more on subjective factors than on the type of physical trauma per se. ${ }^{29}$ Among numerous relevant considerations, the stress criterion was revisited in the DSM-IV. ${ }^{30}$ This came to emphasize the subjective response of the individual to the event (i.e., how threatening and terrifying rather than how "abnormal" - the traumatic event was to the individual).

Individuals use various defensive styles when coping with conflicts in the face of environmental demands. Researchers have demonstrated an association between defense style - mature, immature, or neurotic - and psychopathological severity levels. ${ }^{31}$ Accordingly, in line with the primary objective of this study, we compared patients with a positive diagnosis for ASD vs. those with a negative diagnosis to evaluate their use of defense mechanisms in the face of a traumatic situation. Comparison between the groups revealed a greater use of the mechanisms of undoing (5.0 [3.5-7.0] vs. 7.0 [6.5-8.5]; $p<0.047)$ and devaluation (4.0 [2.5-5.5] vs. 5.0 [5.0-6.5]; $\mathrm{p}<0.047)$ in patients diagnosed with ASD (Table 2). In parallel with our findings, specifically

Table 2 - Defense mechanisms used by patients diagnosed with ASD compared with patients who did not develop the disorder

\begin{tabular}{|c|c|c|c|}
\hline \multirow[b]{2}{*}{ DSQ variable } & \multicolumn{3}{|c|}{ ASD diagnosis } \\
\hline & Negative $(n=136)$ & Positive $(n=10)$ & $\mathbf{p}$ \\
\hline Mature factors & $6.6(5.6-7.2)$ & $6.6(6.0-7.2)$ & 0.865 \\
\hline Anticipation & $7.0(5.0-8.5)$ & $7.0(5.0-7.5)$ & 0.845 \\
\hline Humor & $6.5(5.0-8.0)$ & $8.0(7.5-9.0)$ & 0.134 \\
\hline Suppression & $5.5(5.0-7.0)$ & $5.0(5.0-7.5)$ & 0.940 \\
\hline Sublimation & $7.0(5.0-8.5)$ & $5.0(3.5-8.0)$ & 0.257 \\
\hline Rationalization & $6.5(5.0-8.0)$ & $7.5(5.0-8.5)$ & 0.711 \\
\hline Neurotic factors (mean \pm SD) & $5.34 \pm 1.68$ & $6.23 \pm 1.49$ & 0.108 \\
\hline Pseudo-altruism & $5.5(4.5-7.5)$ & $5.75(5.0-6.5)$ & 0.782 \\
\hline Idealization & $5.0(3.0-7.5)$ & $5.25(5.0-8.5)$ & 0.371 \\
\hline Reaction formation & $5.0(3.5-7.0)$ & $6.0(5.0-9.0)$ & 0.146 \\
\hline Undoing & $5.0(3.5-7.0)$ & $7.0(6.5-8.5)$ & $0.047 *$ \\
\hline Immature factors (mean \pm SD) & $4.31 \pm 1.60$ & $4.97 \pm 1.12$ & 0.232 \\
\hline Projection & $3.0(1.0-5.0)$ & $4.0(3.5-5.0)$ & 0.377 \\
\hline Passive aggression & $4.0(2.5-5.0)$ & $5.0(4.0-5.0)$ & 0.643 \\
\hline Acting out & $5.0(2.0-6.75)$ & $5.0(5.0-5.0)$ & 0.430 \\
\hline Isolation & $5.0(3.0-7.0)$ & $5.0(3.0-9.0)$ & 0.752 \\
\hline Devaluation & $4.0(2.5-5.5)$ & $5.0(5.0-6.5)$ & $0.047 *$ \\
\hline Autistic fantasy & $3.0(2.5-5.5)$ & $5.0(3.5-6.5)$ & 0.401 \\
\hline Denial & $5.0(2.0-6.0)$ & $5.0(3.5-8.5)$ & 0.550 \\
\hline Displacement & $4.0(1.5-5.75)$ & $5.0(1.0-6.5)$ & 0.568 \\
\hline Dissociation & $5.0(3.5-6.5)$ & $5.0(5.0-5.0)$ & 0.728 \\
\hline Splitting & $5.0(3.0-6.25)$ & $5.5(1.0-6.5)$ & 0.653 \\
\hline Somatization & $4.0(1.0-6.5)$ & $5.0(5.0-7.0)$ & 0.099 \\
\hline
\end{tabular}

Data presented as median (25th-75th percentile), unless otherwise specified.

$\mathrm{ASD}=$ acute stress disorder; DSQ = Defensive Style Questionnaire; SD = standard deviation.

$*$ Statistical significant difference between the groups $(p \leq 0.05)$. 
with regard to the undoing mechanism, researchers have examined the relationship between ASD symptoms and anxiety and depression symptoms in children and adolescents aged 8 to 17 after a traumatic event. They reported that symptoms of undoing were positively associated with the sum of symptoms of depression (Spearman's rho $=0.21, \mathrm{p}<0.01$ ) and anxiety (Spearman's rho $=0.33, \mathrm{p}<0.01$ ). ${ }^{29}$ Earlier evidence also suggested that undoing or emotional suppression after a traumatic event is associated with high levels of PTSD symptoms. ${ }^{32}$ We found no studies in the literature up to the time of writing this manuscript that related ASD with the devaluation defense mechanism.

Furthermore, other neurotic and immature factor defensive styles, such as idealization, reaction formation, projection, passive aggression, autistic fantasy, and somatization, were also more used by patients diagnosed with ASD in this study (Table 2), even though the differences were not statistically significant. By comparison, previous research has observed the use of maladaptive defenses, such as isolation, regression, acting out, projection, inhibition, and passive aggression, in war veterans with PTSD, thus diverging from our findings. Such a difference, however, is perhaps understandable as our study did not cover patients diagnosed with PTSD, but rather with ASD. ${ }^{33,34}$

As a secondary objective, we analyzed (Table 3) defense mechanisms of patients with positive ASD symptoms from criterion B of the DSM-5 $(n=21)$ in relation to those with negative criterion $B$ symptoms $(n=122)$. We found evidence that patients with positive criterion B symptoms more often used the mechanisms of idealization and undoing, belonging to the neurotic factor, and projection, passive aggression, autistic fantasy, and somatization, belonging to the immature factor. Thus, we can speculate that the less adapted the individual is to reality, the more immature the defenses used will be and the lower the quality of conflict management. Also, this opens up the possibility of different, or altered, personality functioning in patients with positive criterion B symptoms. Further studies are required to verify this matter.

We also observed that the use of immature defense mechanisms was correlated more intensely with

Table 3 - Defense mechanisms used by patients with ASD symptoms from criterion B of the DSM- 5 compared to patients without those criterion B symptoms

\begin{tabular}{|c|c|c|c|}
\hline \multirow[b]{2}{*}{ DSQ variable } & \multicolumn{3}{|c|}{ ASD symptoms from criterion B of the DSM-5 } \\
\hline & $\begin{array}{c}\text { Negative ( }<9 \text { symptoms }) \\
(n=122)\end{array}$ & $\begin{array}{c}\text { Positive ( } \geq 9 \text { symptoms) } \\
(\mathrm{n}=21)\end{array}$ & $\mathbf{p}$ \\
\hline Mature factors & $6.6(5.6-7.2)$ & $6.6(5.4-7.2)$ & 0.950 \\
\hline Anticipation & $6.75(5.0-8.5)$ & $7.5(5.0-8.5)$ & 0.557 \\
\hline Humor & $6.5(5.0-8.0)$ & $7.0(5.0-9.0)$ & 0.682 \\
\hline Suppression & $5.75(5.0-7.5)$ & $5.0(5.0-6.0)$ & 0.395 \\
\hline Sublimation & $7.0(5.0-8.5)$ & $7.0(5.0-8.5)$ & 0.829 \\
\hline Rationalization & $6.5(5.0-8.5)$ & $6.5(5.0-8.0)$ & 0.223 \\
\hline Neurotic factors (media \pm SD) & $5.24 \pm 1.67$ & $6.31 \pm 1.38$ & $0.005^{*}$ \\
\hline Pseudo-altruism & $5.0(4.5-7.0)$ & $6.0(5.0-8.0)$ & 0.125 \\
\hline Idealization & $5.0(3.0-7.0)$ & $6.75(5.0-8.5)$ & $0.024^{*}$ \\
\hline Reaction formation & $5.0(3.5-7.0)$ & $5.0(4.0-8.0)$ & 0.425 \\
\hline Undoing & $5.0(3.0-7.0)$ & $6.75(5-8.5)$ & $0.004 *$ \\
\hline Immature factors (media \pm SD) & $4.21 \pm 1.58$ & $4.61 \pm 1.34$ & $0.007^{*}$ \\
\hline Projection & $2.5(1.0-5.0)$ & $4.5(3.5-7.25)$ & $0.005^{*}$ \\
\hline Passive aggression & $4.0(2.5-5.0)$ & $5.0(3.75-6.25)$ & $0.030 *$ \\
\hline Acting out & $4.5(2.0-6.0)$ & $5.0(5.0-8.25)$ & 0.070 \\
\hline Isolation & $5.0(3.0-7.0)$ & $5.0(3.0-7.75)$ & 0.676 \\
\hline Devaluation & $4.0(2.5-5.0)$ & $5.0(4.25-6.25)$ & 0.087 \\
\hline Autistic fantasy & $3.0(1.0-5.0)$ & $5.0(3.5-7.0)$ & $0.049 *$ \\
\hline Denial & $5.0(2.0-6.0)$ & $5.0(3.25-7.5)$ & 0.332 \\
\hline Displacement & $4.0(1.5-5.5)$ & $5.0(3.25-7.0)$ & 0.116 \\
\hline Disassociation & $5.0(3.5-6.0)$ & $5.0(4.0-7.25)$ & 0.477 \\
\hline Splitting & $5.0(3.0-6.5)$ & $5(1.5-6.5)$ & 0.077 \\
\hline Somatization & $4(1.0-5.5)$ & $5.0(4.75-7.75)$ & $0.017^{*}$ \\
\hline
\end{tabular}

Data presented as median (25th-75th percentile), unless otherwise specified.

$\mathrm{ASD}=$ acute stress disorder; DSQ = Defensive Style Questionnaire; SD = standard deviation.

$*$ Statistical significant difference between the groups $(p \leq 0.05)$. 
patients with criterion B symptoms ( $p<0.001)$, with the following mechanisms being positively correlated: projection, passive aggression, acting out, displacement, somatization, autistic fantasy, and undoing (Table 4). Similar to our results, a previous study investigated the association of defense mechanisms with the occurrence of specific psychiatric symptoms in a population of 201 North Korean refugees and found evidence of a positive correlation of PTSD with the mechanisms of isolation and undoing, after controlling for anxiety and depression. ${ }^{34}$

The mechanisms referred to in this study are present in diverse functional and personality styles, however they are more active in individuals who possess a personality structure considered regressive. ${ }^{35}$ These more regressive mechanisms are used and mustered with greater predominance when the ego's other internal resources cannot deal with a traumatic situation in a more adaptive way. The use of such defenses arises, thus, as an attempted coping strategy for controlling anguish and anxiety, and for facing, accepting, ignoring, or suppressing the potential threat experienced at that moment, which, in many cases, results in pathology due to the intensity and rigidity present in the operating personality of the subject. Earlier research bolsters this assertion supporting the idea that immature defense mechanisms (as well as neurotic ones) are considered pathological and associated with high anxiety levels. ${ }^{16,20,36}$

Another noteworthy defense mechanism in traumatized patients, particularly in those who develop PTSD, is dissociation. When people experience "vociferous emotions," their psychic apparatus searches for an alternative way to deal with the excessive situation. This is unnamed at the time, disassembling the traumatic experience, and casting it into different dimensions of the unconscious. As a result, the memories of the traumatic experience cannot be integrated into consciousness and remain dissociated from it. Freud (1926/1996) also recognized that something becomes traumatic because it stays dissociated and out of conscious perception. ${ }^{37}$ However, even though dissociative symptoms are diagnostic criteria for $A S D,{ }^{9}$ in this study no significant differences were found in the use of the dissociation mechanism between cases and controls.

Regarding psychiatric comorbidities (Table 5), several studies in the area of trauma have shown that these rates can be up to two times greater in trauma victims. ${ }^{10,38,39}$ Furthermore, a previous study that

Table 4 - Association between number of ASD symptoms from criterion B of the DSM-5 and defense mechanisms assessed by the DSQ

\begin{tabular}{lcc}
\hline DSQ & Spearman's rho & p \\
\hline Mature factors & 0.121 & 0.150 \\
Anticipation & 0.190 & 0.022 \\
Humor & 0.06 & 0.472 \\
Suppression & 0.027 & 0.751 \\
Sublimation & 0.101 & 0.226 \\
Rationalization & -0.033 & 0.690 \\
Neurotic factors & 0.375 & $<0.001$ \\
Pseudo-altruism & 0.218 & 0.008 \\
Idealization & 0.273 & 0.001 \\
Reaction formation & 0.207 & 0.012 \\
Undoing & 0.364 & $<0.001$ \\
Immature factors & 0.493 & $<0.001$ \\
Projection & 0.500 & $<0.001$ \\
Passive aggression & 0.421 & $<0.001$ \\
Acting out & 0.344 & $<0.001$ \\
Isolation & 0.131 & 0.114 \\
Devaluation & 0.220 & 0.007 \\
Autistic fantasy & 0.329 & $<0.001$ \\
Denial & 0.235 & 0.004 \\
Displacement & 0.373 & $<0.001$ \\
Dissociation & 0.159 & 0.055 \\
Splitting & 0.248 & 0.003 \\
Somatization & 0.369 & $<0.001$ \\
\hline
\end{tabular}

ASD = acute stress disorder; DSQ = Defensive Style Questionnaire. 
analyzed 125 automobile accident survivors, of whom $40.9 \%$ presented diagnostic criteria for ASD, found that the predictors were: anxiety, suicide risk, and traumatic reinterpretation. ${ }^{31}$ Additionally, in a cohort study involving 450 employees of the Danish Bank exposed to bank robbery in Denmark, sensitive anxiety, peritraumatic panic, and negative self-perception were considered risk factors for developing severe
ASD in $74 \%$ of cases. ${ }^{27}$ Confirming the findings in the literature, the present study found a greater prevalence of psychiatric comorbidities, such as current depression, current melancholy, suicide risk, history of panic attack, agoraphobia without panic attack, social phobia, current PTSD, history of psychosis, psychotic mood, and history of psychotic mood, in patients with ASD as compared to those without this diagnosis (Table 5).

Table 5 - Relationship between groups evaluated for ASD and statistically relevant psychiatric comorbidities

\begin{tabular}{|c|c|c|c|}
\hline \multirow[b]{2}{*}{ Variables } & \multicolumn{3}{|c|}{ ASD diagnosis } \\
\hline & Negative $(n=136)$ & Positive $(n=10)$ & $\mathbf{p}$ \\
\hline \multicolumn{4}{|l|}{ MINI diagnosis } \\
\hline Depression (current) & $34(25.0)$ & $7(70.0)$ & 0.013 \\
\hline Melancholy (current) & $24(17.6)$ & $6(60.0)$ & 0.007 \\
\hline Suicide risk $(n=125)$ & $28(22.4)$ & $6(60.0)$ & 0.030 \\
\hline Panic disorder history $(n=145)$ & & & 0.031 \\
\hline Yes & $15(11.1)$ & $3(30.0)$ & \\
\hline No & $118(87.4)$ & $6(60.0)$ & \\
\hline Not applicable & $2(1.5)$ & $0(0)$ & \\
\hline Panic attack (current) $(n=145)$ & & & 0.006 \\
\hline Yes & $5(3.7)$ & $2(20.0)$ & \\
\hline No & $126(93.3)$ & $6(60.0)$ & \\
\hline Not applicable & $4(3.0)$ & $2(20.0)$ & \\
\hline Agoraphobia without panic & & & 0.001 \\
\hline Yes & $21(15.4)$ & $7(70.0)$ & \\
\hline No & $113(83.1)$ & $3(30.0)$ & \\
\hline Not applicable & $2(1.5)$ & $0(0)$ & \\
\hline Social phobia $(n=145)$ & & & 0.001 \\
\hline Yes & $16(11.9)$ & $6(60.0)$ & \\
\hline No & $116(85.9)$ & $4(40.0)$ & \\
\hline Not applicable & $3(2.2)$ & $0(0)$ & \\
\hline PTSD (current) & & & 0.029 \\
\hline Yes & $10(7.4)$ & $2(20.0)$ & \\
\hline No & $125(91.9)$ & $7(70.0)$ & \\
\hline Not applicable & $1(0.7)$ & $1(10.0)$ & \\
\hline Psychosis history $(n=144)$ & & & 0.031 \\
\hline Yes & $30(22.4)$ & $6(60.0)$ & \\
\hline No & $103(76.9)$ & $4(40.0)$ & \\
\hline Not applicable & $1(0.7)$ & $0(0)$ & \\
\hline Psychotic mood $(n=144)$ & & & 0.031 \\
\hline Yes & $13(9.7)$ & $4(40.0)$ & \\
\hline No & $119(88.8)$ & $6(60.0)$ & \\
\hline Not applicable & $2(1.5)$ & $0(0)$ & \\
\hline Psychotic mood history $(n=144)$ & & & 0.021 \\
\hline Yes & $15(11.2)$ & $5(50.0)$ & \\
\hline No & $116(86.6)$ & $5(50.0)$ & \\
\hline Not applicable & $2(1.5)$ & $0(0)$ & \\
\hline
\end{tabular}

Data presented as $\mathrm{n}(\%)$.

$\mathrm{ASD}=$ acute stress disorder; MINI = Mini-International Neuropsychiatric Interview.

254 - Trends Psychiatry Psychother. 2017;39(4) 
Waqas et al. analyzed defense mechanisms such as depression, anxiety, and academic performance in a population of medical students continuously exposed to this stressful area of education. ${ }^{36}$ Those authors found that the use of immature and neurotic defensive styles was associated with low academic performance and high levels of depression and anxiety. It was noted that, owing to such a result, individuals subjected to stressful situations (traumatic or not) are more vulnerable to developing pathologies such as depression and anxiety when they employ immature and neurotic defenses.

Psychological factors, as well as mental disorders, such as ASD, in addition to constituting an important mental health problem, could impair the patient's clinical recovery. ${ }^{40}$ Similarly, it is known that early interventions can prevent the negative evolution of the ASD framework into PTSD. ${ }^{8}$

One of the limitations of this study is that it was an exploratory cross-sectional study that resulted in asymmetric group sizes. Despite the fact that appropriate statistical tests were used, this limitation prevents generalizing results or making further assumptions related to the findings.

\section{Conclusion}

In the present study, patients with ASD made greater use of defense mechanisms of the undoing and devaluation type as compared to patients not diagnosed with ASD. Thus, the relevance of these discoveries is directly related to the need for early detection of ASD symptoms, enabling preventive action, and thereby making early treatment possible. This could avoid additional harm linked to trauma and would represent an important advance in terms of global public health in the assistance of trauma victims. The present study may also pave the way for future personality research with ASD patients.

\section{Acknowledgements}

This study received financial support from Fundo de Incentivo a Pesquisa - Hospital de Clínicas de Porto Alegre (FIPE-HCPA; grant 110533).

We would like to thank all the patients who, at a time of vulnerability in their lives, were willing to contribute to our research, to the professionals who collected data, and to the research group who undertook this work with commitment and dedication. We also thank Cary Collet for the translation of this work.

\section{Disclosure}

No conflicts of interest declared concerning the publication of this article.

\section{References}

1. Laplanche J, Pontalis JB. Vocabulário de psicanálise. $3^{a}$ ed. São Paulo: Martins Fontes; 1998.

2. Freud S. Além do princípio do prazer. In: Freud S. Obras completas de Sigmund Freud. Rio de Janeiro: Imago; 1920/1996. v. XVII.

3. Schestatsky S, Shansis F, Ceitlin LH, Abreu PB, Hauck S. [Historical evolution of the concept of posttraumatic stress disorder]. Rev Bras Psiquiatr. 2003;25:8-11.

4. Eizirik M, Schestatsky S, Knijnik L, Terra L, Ceitlin LHF Contratransferência e trauma psíquico. Rev Psiquiatr Rio Gd Sul. 2006;28:314-20.

5. American Psychiatric Association. Diagnostic and Statistical Manual of Mental Disorders, Third Edition (DSM-III). Washington: American Psychiatric Publishing; 1980.

6. Bunting BP, Ferry FR, Murphy SD, O'Neill SM, Bolton D. Trauma associated with civil conflict and posttraumatic stress disorder: evidence from the Northern Ireland study of health and stress. J Trauma Stress. 2013;26:134-41.

7. Hexsel AM, Hexsel CL. Transtorno do stress agudo. In: Cataldo Neto A, Gauer GJC, Furtado NR. Psiquiatria para estudantes de medicina. Porto Alegre: Edipucrs; 2003. p. 445-50.

8. Creamer M, O'Donell ML, Pattison P. The relationship between acute stress disorder and posttraumatic stress disorder in severely injured trauma survivors. Behav Res Ther. 2004;42:315-28.

9. American Psychiatric Association. Diagnostic and Statistical Manual of Mental Disorders, Fifth Edition (DSM-5). Arlington: American Psychiatric Publishing; 2013.

10. Bryant RA, Friedman MJ, Spiegel D, Ursano R, Strain J. A review of acute stress disorder in DSM-5. Depress Anxiety. 2011;28:802-17.

11. Harvey AG, Bryant RA. Predictors of acute stress following motor vehicle accidents. J Trauma Stress. 1999;12:519-25.

12. Harvey AG, Bryant RA. Two-year prospective evaluation of the relationship between acute stress disorder and posttraumatic stress disorder following mild traumatic brain injury. Am J Psychiatry. 2000;157:626-8.

13. Bryant RA. Acute stress disorder as a predictor of posttraumatic stres disorder: a systematic review. J Clin Psychiatry. 2011;72:233-9.

14. Hansen M, Armour C, Wittmann L, Elklit A, Shevlin M. Is there a common pathway to developing ASD and PTSD symptoms? J Anxiety Disord. 2014;28:865-72.

15. Freud S. Inibição, sintoma e ansiedade. In: Freud S. Obras completas de Sigmund Freud. Rio de Janeiro: Imago; 1926/1996. vol. 20.

16. Vaillant GE. Adaptive mental mechanisms. Their role in a positive psychology. Am Psychol. 2000;55:89-98.

17. Metzger JA. Adaptive defense mechanisms: function and transcendence. J Clin Psychol. 2014;70:478-88.

18. Galduróz JC, Noto AR, Carlini EA. IV Levantamento sobre o uso de drogas entre estudantes de $1^{\circ}$ e $2^{\circ}$ graus em 10 capitais brasileiras. São Paulo: Centro Brasileiro de Informações sobre Drogas Psicotrópicas, Departamento de Psicobiologia, Escola Paulista de Medicina; 1997.

19. Bond M, Gardner ST, Christian J, Sigal JJ. Empirical study of selfrated defense styles. Arch Gen Psychiatry. 1983;40:333-8.

20. Vaillant GE, Bond M, Vaillant CO. An empirically validated hierarchy of defense mechanisms. Arch Gen Psychiatry. 1986;43:786-94.

21. Andrews $G$, Singh $M$, Bond $M$. The defense style questionnaire. J Nerv Ment Dis. 1993;181:246-56.

22. Andrade MPM. Tradução e adaptação do DSQ (Defense Style Questionnaire) para uso no Brasil [dissertação]. São Paulo: Universidade Federal de São Paulo; 1996.

23. Andrade M, Shirakawa I. Versão brasileira do Defense Style Questionnaire (DSQ) de Michael Bond: problemas e soluções. Rev Psiquiatr Rio Gd Sul. 2006;28:144-60.

24. Blaya C, Kipper L, Heldt E, Isolan L, Ceitlin LH, Bond M, et al. [Brazilian-Portuguese version of the Defense Style Questionnaire (DSQ-40) for defense mechanisms measure: a preliminary study]. Rev Bras Psiquiatr. 2004;26:255-8. 
25. Hair FJ, Black WC, Babin B, Anderson RE, Tathan RL. Análise multivariada de dados. 6a ed. Porto Alegre: Bookman; 2009.

26. Bryant RA, Creamer M, O`Donnell M, Silove D, McFarlane AC. The capacity of acute stress disorder to predict posttraumatic psychiatric disorders. J Psychiatr Res. 2011;46:168-73.

27. Hansen M, Armour C. Assessing DSM-5 latent subtypes of acute stress disorder dissociative or intrusive? Psychiatry Res. 2014;225:476-83.

28. Barber $A B$, Kohl KL, Kassam-Adams N, Gold JI. Acute stress, depression, and anxiety symptoms among English and Spanish speaking children with recent trauma exposure. J Clin Psychol Med Settings. 2014;21:66-71.

29. Gauer GJC, Diefenthaeler J, Ceitlin LHF. Transtorno de estresse pós traumático. In: Cataldo Neto A, Gauer GJC, Furtado NR. Psiquiatria para estudantes de medicina. Porto Alegre: Edipucrs; 2013. p. 413-21.

30. American Psychiatric Association. Diagnostic and Statistical Manual of Mental Disorders, Fourth Edition (DSM-IV). Arlington: American Psychiatric Publishing; 1994.

31. Suliman S, Troeman Z, Stein DJ, Seedat S. Predictors of acute stress disorder severity. J Affect Disord. 2013;149:277-81.

32. Seligowski AV, Miron LR, Orcutt HK. Relations among selfcompassion, PTSD symptoms, and psychological health in a trauma-exposed sample. New York: Springer Science Business Media; 2014.

33. Silverstein R. Combat-related trauma as measured by ego developmental indices of defenses and identity achievement. J Genet Psychol. 1996;157:169-79.
34. Jun JY, Lee YJ, Lee SH, Yoo SY, Song J, Kim SJ. Association between defense mechanism and psychiatric symptoms in North Korean refugees. Compr Psychiatry. 2015;56:179-87.

35. Bergeret, J. Psicopatologia - teoria e clínica. 9a ed. Porto Alegre: Artmed; 2006.

36. Waqas A, Rehman A, Malik A, Muhammad U, Khan S, Mahmood N. Association of ego defense mechanisms with academic performance, anxiety and depression in medical students: a mixed methods study. Cureus. 2015;7:e337.

37. Freud S. Três Ensaios sobre a sexualidade. In: Freud S. Obras completas de Sigmund Freud. Rio de Janeiro: Imago; 1905/1996. vol. VII.

38. Friedman $M J$, Yehuda R. Post traumatic stress disorders and comorbidity: psychobiological approaches to differential diagnosis. In: Friedman MJ, Charney DS, Deutch AY. Neurobiological and clinical consequences of stress. Philadelphia: Lippincott-Raven; 1995. p. 429-45.

39. McFarlane AC, Papay P. Multiple diagnoses in posttraumatic stress disorder in the victims of a natural disaster. J Nerv Ment Dis. 1992;180:498-504.

40. Romano WB. Manual de psicologia clínica para hospitais. São Paulo: Casa do Psicólogo; 2008.

\section{Correspondence:}

Cleonice Zatti

E-mail: cleonice.zatti@outlook.com 